\title{
JOGOS DIGITAIS: UM REFORÇO NO ENTENDIMENTO DE FLUXOGRAMAS EM
} PROCESSOS DE NEGÓCIO

\author{
João Cezario Giglio Marques \\ Universidade do Oeste Paulista - UNOESTE, Faculdade de Informática de Presidente Prudente - FIPP, Presidente \\ Prudente, SP. E-mail: cezario@unoeste.br
}

\section{RESUMO}

Este artigo revisou e descreveu os conceitos de gamificação e suas aplicações na educação, principalmente no reforço da aprendizagem de processos de negócios por meio de fluxogramas. A presente pesquisa destaca as principais características e qualidades dos jogos digitais e suas vantagens na motivação e envolvimento interativo dos estudantes das áreas de Administração, Informática, Engenharia, Agronomia, Zootecnia incluindo-se ai todas as disciplinas envolvidas com processos. A aplicação desta tecnologia é implementada e desenvolvida por meio de um storyboard contendo a descrição de todas as jogadas para implementação do Game.

Palavras-chave: Gamificação; Jogos Digitais; Educação; Processos de Negócio; Fluxograma.

DIGITAL GAMES: AN INCREASE IN FLOW CHARTS OF UNDERSTANDING IN BUSINESS PROCESSES

\begin{abstract}
This research reviewed and described the concepts of gamification and its applications in education, especially in enhancing business processes learning through flowcharts. This research highlights the main features and qualities of digital games and their advantages in motivating and interactive engagement of students in the areas of Administration, Information Technology, Engineering, Agronomy, Animal Science including up there all the disciplines involved with processes. Application of this technology is implemented and developed through a storyboard containing the description of all the moves to implement the game.
\end{abstract}

Keywords: gamification; Digital games; education; Business processes; Flowchart 


\section{INTRODUÇÃo}

O termo "gamificação" (do original inglês: gamification) significa a aplicação de elementos utilizados no desenvolvimento dos jogos digitais, envolvendo principalmente mecânica e dinâmica.

Motivados pelo crescente número de pesquisas sobre gamificação em outras áreas, esta pesquisa se torna relevante à medida que o interesse pela gamificação e seu emprego têm aumentado também na área de educação, principalmente, pelo potencial da gamificação para influenciar, engajar e motivar os alunos.

Estudos sobre o uso de jogos e elementos de jogos em educação vêm sendo realizados há algumas décadas, porém nos últimos anos o interesse pelo tema vem aumentando em ritmo acelerado gerando inúmeros debates acerca do tema.

Com o intuito de preencher tal lacuna, foi realizada uma pesquisa bibliográfica baseandose na leitura das pesquisas existentes envolvendo gamificação e educação e, em um segundo momento foi organizado um game aliando teoria à prática.

O público-alvo definido como usuários do game são os alunos do curso de bacharelado em Sistemas de Informação, das disciplinas de Teoria Geral dos Sistemas e Organização e Métodos.

O propósito central é o de aperfeiçoar o ambiente virtual de aprendizagem através de um jogo educativo que permita uma aprendizagem mais interativa e lúdica.

\section{METODOLOGIA}

Foram utilizadas a metodologia de pesquisa exploratória na Internet e consulta no material bibliográfico disponível. A partir deste referencial teórico organizado, concebeu-se a consequente aplicação da gamificação, resultando em um projeto estruturado de desenvolvimento de um game para servir de reforço no ensino de processos de negócios, com a utilização de fluxogramas.

\section{RESULTADOS}

\subsection{Jogos Enquanto Mídia}

Este artigo tem como objetivo contribuir para a aprendizagem de processos de negócios por meio de mídia interativa em forma de um jogo digital.

A mídia em comunicação refere-se aos canais ou as ferramentas usadas para armazenamento e transmissão de informação ou dados. O termo mídia muitas vezes é usado como sinônimo de meios de comunicação de massa, mas pode se referir a um único meio utilizado para comunicar os dados para qualquer finalidade. 
Ao fazer parte do processo de comunicação a mídia contempla todos os elementos da comunicação, como emissor, mensagem e receptor.

Neste mesmo contexto as tecnologias da informação e da comunicação (TICs) transformaram inúmeros aspectos da sociedade. A contribuição para área da educação tem sido significativa, principalmente com as várias mídias disponíveis.

As TICs transformaram diversos aspectos da vida, alteraram o mundo do trabalho, da produção científica, do lazer, da cultura, o mundo econômico, político e o ensino. As TICs transformaram a maior parte das atividades nas ultimas décadas, mesmo não estando ao alcance de todos os indivíduos ou grupos é inegável a influência das TICs no mundo atual. (SANCHO; HERNÁNDEZ, 2006 apud GRIMM; CALOMENO, 2009, p. 02).

A palavra jogo é originária do latim: iocus, iocare e significa brinquedo, folguedo, divertimento, passatempo sujeito a regras, ou até mesmo uma série de ocorrências que formam uma coleção. Lúdico vem do latim ludus, que significa: exercício, drama, teatro, circo e significa também exercício escolar (magister ludi).

Para Piaget (1972) o lúdico tem as funções de consolidar as ações individuais aprendidas e proporcionar prazer e equilíbrio funcional ao aprendiz. Segundo Lèvy (1998), os jogos funcionam como elementos de construção e reorganização de funções cognitivas, tais como memória, atenção, criatividade e imaginação, determinando a forma de percepção e compreensão da pessoa em relação ao objeto.

\subsection{O STORYBOARD DO JOGO}

Esta etapa tem por objetivo descrever os elementos relacionados ao jogo educativo desenvolvido e proposto como prática do trabalho. A ideia surgiu decorrente da dificuldade dos alunos em associar situações descritas em um processo de negócio, a sua sequencia lógica e sua relação com a simbologia de fluxograma de processo.

Inicia-se com as descrições de situações comuns e cotidianas. Tem o objetivo de entender, unificar, analisar relacionamentos do sistema a ser construído. Descreve também as interações entre componentes do sistema. A tabela 01 apresenta todos os elementos que estruturam o jogo. 
Tabela 01. Estrutura do Jogo

\begin{tabular}{|c|l|}
\hline Título & \multicolumn{1}{|c|}{$\begin{array}{l}\text { Game de reforço à aprendizagem de fluxograma de processo de } \\
\text { negócio }\end{array}$} \\
\hline Contexto & $\begin{array}{l}\text { Iniciar e finalizar um processo de negócio em um ambiente } \\
\text { empresarial por intermédio de simbologia de fluxograma de } \\
\text { processo. }\end{array}$ \\
\hline Atores & $\begin{array}{l}\text { São pessoas com cargos e funções compatíveis com o seu papel } \\
\text { no processo. No caso são: vendedor e mecânico }\end{array}$ \\
\hline Recursos & São os símbolos de fluxograma e enunciados correspondentes. \\
\hline Episódios & $\begin{array}{l}\text { Cada personagem tem ações a serem desenvolvidas em ordem } \\
\text { sequencial correspondente às necessidades do processo. }\end{array}$ \\
\hline Restrições & $\begin{array}{l}\text { Não utilizar o símbolo correspondente e na sequencia } \\
\text { programada impede do jogador prosseguir. }\end{array}$ \\
\hline Feedback & Fornecer a causa do erro e sugerir o passo correto. \\
\hline
\end{tabular}

Fonte: Autoria própria.

\subsubsection{Objetivo do jogo}

Habilitar estudantes da área de negócio e processo a entenderem e modelarem um processo de negócio através da técnica da fluxogramação para entender as sequencias e fases do processo, integrando-os de forma a possibilitar:

- $\quad$ Treinar pessoas que interagem com o processo;

- $\quad$ Corrigir eventuais re-trabalhos

- Melhorar o processo

- $\quad$ Analisar a participação de cada executor no processo;

- Informatizar e racionalizar o processo

Atividades realizadas no jogo:

Cada jogada é feita com um único jogador. Existe um ambiente com os personagens, várias operações dispostas de forma randômica e os símbolos disposto igualmente de forma randômica.

O storyboard a seguir descreve a dinâmica do jogo, iniciando-se com a figura 01, que apresenta o jogo e suas regras. 
Figura 01. Regras do jogo

Contexto do jogo: O cliente, que é representado pelo aluno-aprendiz, vai descrever o processo para aquisição e instalação de pneus e serviços automotivos.

0 ambienteserá o de uma recepçãocom um vendedor euma oficina mecânica co m um mecânico.

Objetivo: Estimular a ação sequencial correta para que a totalidade do processo

seja descritoe codificado em simbologiade diagrama de fluxograma.

Etapa I-Cumprir todas as ações correspondentes à interação cliente-vendedor e

associar ao símbolo correto correspondente à açãocom acerto.

Etapa II-Cumprir todas as ações correspondentes à interação cliente-mecânico e

associar ao símbolo correto correspondente á ação com acerto

Jogar

Fonte: autoria própria

A seguir, descreve-se a simbologia de fluxograma a se utilizada no jogo.

Figura 02. Simbologia de fluxograma

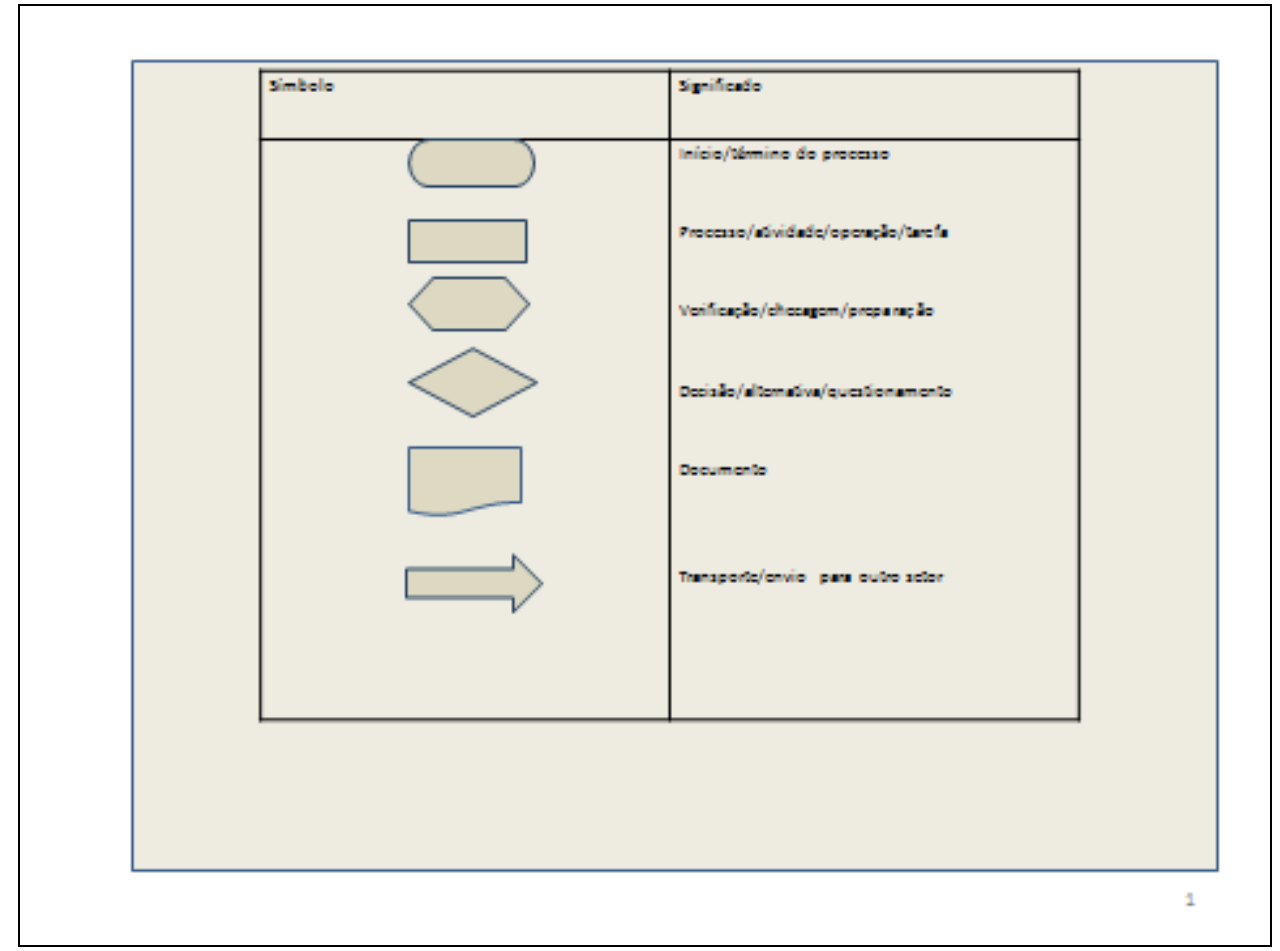

Fonte: Autoria própria. 
Figura 03. Descrição do processo do jogo

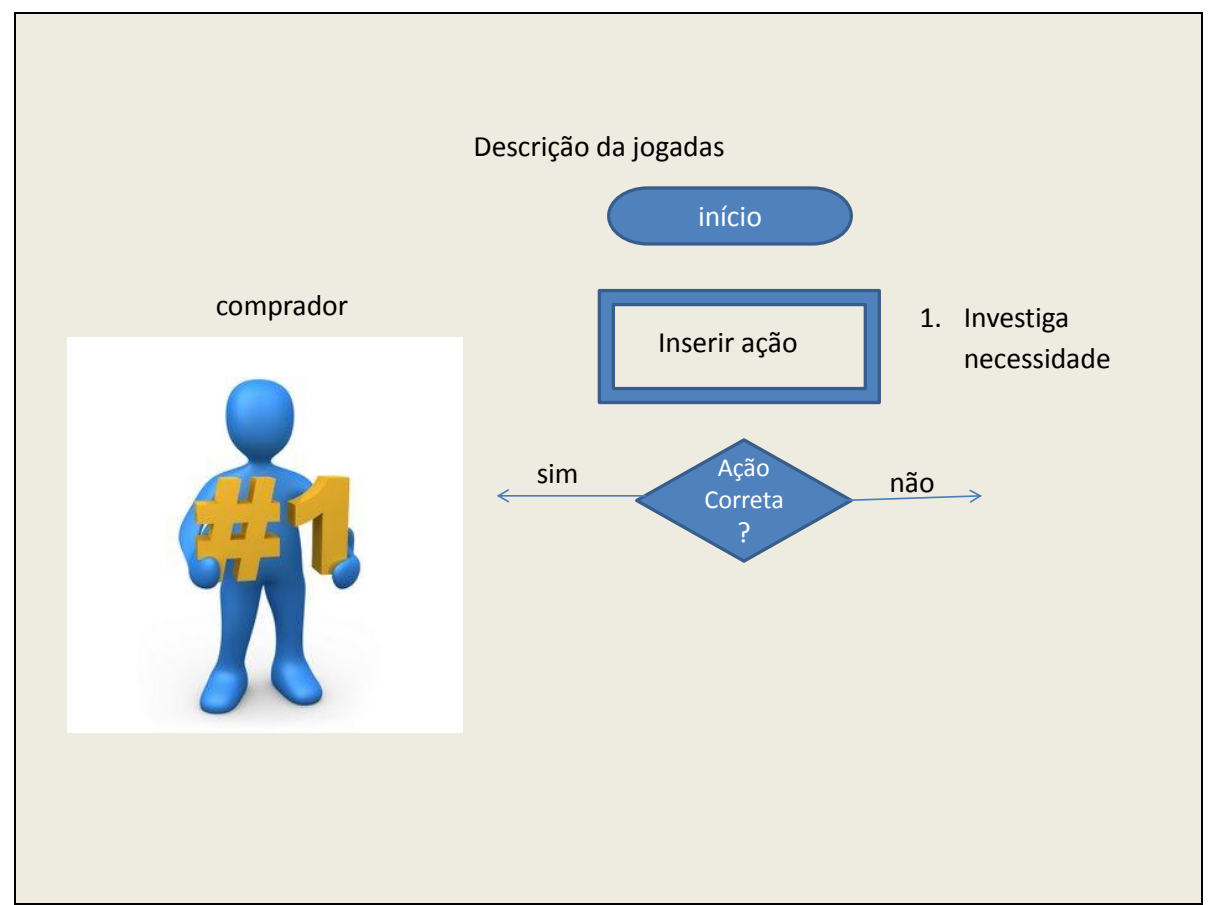

Fonte: Autoria própria.

Figura 04. Descrição das ações do processo de negócio

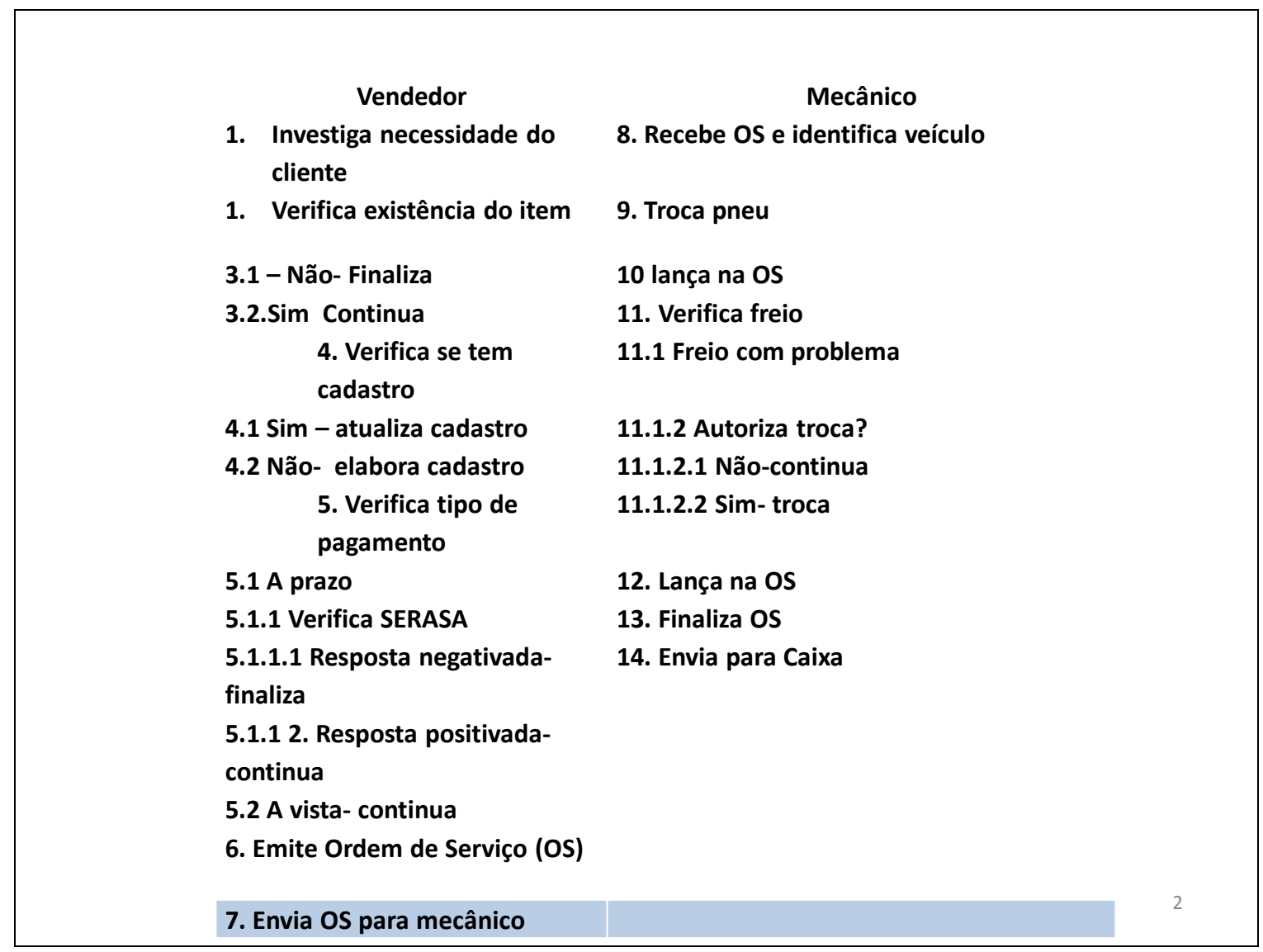

Fonte: Autoria própria. 
Figura 5. Fluxograma do jogo

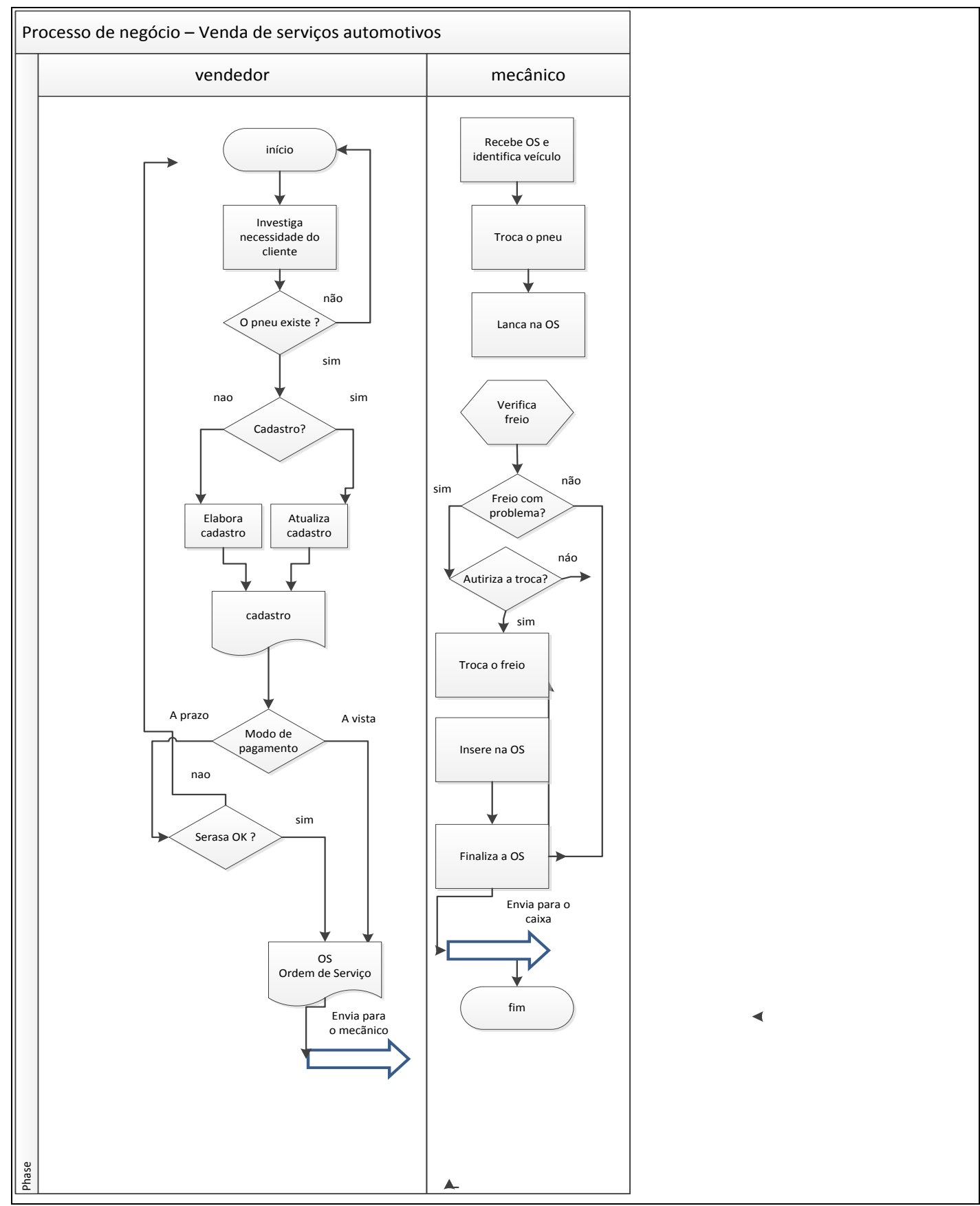

Fonte: Autoria própria.

Finalizando este capítulo, consubstanciado por todo o aporte teórico, indica-se a possibilidade de melhorar a interação entre os elementos que compõe o sistema de ensinoaprendizagem. Ao perceber que um todo complexo compõe-se de ações simples, estimula-se os alunos a perceber uma sequencia logica destas ações e associar aos símbolos, que representa a síntese do conhecimento do processo. É um conjunto de soluções percebido e absorvido de forma estimulante, dinâmica, mecânica e esteticamente atraente. 
DISCUSSÃO:

A pesquisa e a proposta resultante indicou a possibilidade de poder inovar-se no ambiente de ensino e aprendizagem. O passo seguinte é implementar o jogo de forma que inicie a sua aplicação e que seja medido os seus resultados, com vários grupos e os necessários grupos de controle.

\section{CONCLUSÃO}

O trabalho abordou de forma conceitual a mídia dos jogos digitais aplicado em um contexto educacional. Descreveu o fenômeno da gamificação. Os benefícios de engajamento dos alunos foi o vetor mais motivador deste trabalho. $O$ desenvolvimento das habilidades de modelar os processos de negócios tem como reforço o jogo de Processo de Negócios.

Durante a minha vida profissional de professor de fluxogramas tenho constatado reações de espanto e certa resistência nos estudantes ao se deparar com a complexidade de um processo de negócio, sua sequencia lógica e sua simbologia no momento de decodificar as ações.

Essa foi à inspiração para o trabalho, direcionado ao mundo dos negócios e a compreensão. Os fluxogramas permitem simplificar a realidade, compreende-la, modifica-la, informatiza-la ou melhora-la.

\section{REFERÊNCIAS}

BALDAM, Roquemar de Lima et al. Gerenciamento de processos de negócios: BPM - business process management. 2. ed. São Paulo: Érica, 2007.

CARVALHO, Fabricia Silva de Carvalho; HAGUENAUER, Cristina Jasbinscheck; VICTORINO, Ana Lúcia Quental. Utilização de Jogos Interativos no Ensino a Distância. Maio 2005 Disponível em: <http://www.abed.org.br/congresso2005/por/pdf/040tcc5.pdf> Acesso em: 12 jan 2015.

ESPER, Marcio. Uma pequena introdução ao desenvolvimento de jogos de computador. Parte 5. Código. 07 jul 2012. Disponível em: < http://www.hardware.com.br/guias/uma-pequenaintroducao-desenvolvimento-jogos-computador/criacao-storyboard.html> Acesso em $01 \mathrm{fev}$. 2015.

FARDO, Marcelo Luis. A gamificação aplicada em ambientes de aprendizagem. CINTED-UFRGS. Novas Tecnologias na educação. V. 11 № 1, julho, 2013.

GRIMM, Gabrielle Hartmann; CALOMENO, Carolina. Fundamentos para análise de Jogos

Educacionais Digitais: aproximações da teoria semiótica e da mente representacional. Universidade Positivo. Intercom - Sociedade Brasileira de Estudos Interdisciplinares da Comunicação. XXXII Congresso Brasileiro de Ciências da Comunicação - Curitiba, PR - 4 a 7 de setembro de 2009. 